\title{
Coupled Dynamic Behaviour of a Transmission System with Gear Eccentricities for a High-Speed Train
}

\author{
Zhiwei Wang ${ }^{\mathrm{a}}$, Zhonghui Yin ${ }^{\mathrm{a}}$, Ruicheng Wang ${ }^{\mathrm{b}}$, Yao cheng ${ }^{\mathrm{a}}$, Paul Allen ${ }^{\mathrm{b}}$,Weihua Zhang ${ }^{\mathrm{a}}$ \\ aState Key Laboratory of Traction Power, Southwest Jiaotong University, Chengdu, Sichuan \\ 610031, China. \\ ${ }^{\mathrm{b}}$ Institute of Railway Research, University of Huddersfield, Huddersfield, HD1 3DH, UK.
}

\section{Abstract}

The transmission system of a motor car directly affects the operating reliability and running safety of a high-speed train. This study examines the coupled torsion vibration responses of a transmission system in a vehicle-track vibration environment. It considers the time-varying mesh stiffness, nonlinear damping characteristics, wheel flexible deformation and wheel-rail interactions. The results are compared to those of previous works as a means of validation. Then, the dynamic characteristics of the transmission system and its coupling effects are investigated along with gear eccentricity, which describes the torsional vibration properties in the vehicle-track coupled system more comprehensively. The results show that the traction torque and gear eccentricity affect the gear meshing, vibration amplitudes and frequency multiplication of the transmission system during the vehicle acceleration process. The eccentricity, especially of the pinion, has a great effect on vibration in the transmission system at high speed ranges. Also, the dynamic responses of the wheels of the same motor car wheelset are different under traction conditions, which should not be neglected when assessing the torsional dynamic performance. The model provides a useful source of reference for the design and condition monitoring of traction systems for high-speed trains.

Keywords: traction transmission system, eccentricity, flexible wheelset, vibration environments, high-speed train.

\section{Introduction}

Compared with trailer cars, the motor car of a high-speed train has an additional traction transmission system because of its functional differences. The traction transmission system comprises a traction motor, flexible coupling, gearbox and wheelset. During operation, the traction torque of the motor is transmitted to the pinion of the gearbox through a flexible coupling, and it is then delivered to the driven gear by gear meshing to drive the wheelset. The dynamic performance of the transmission system plays an important role in the running safety of a high-speed train [1]. With increasing running speed, the traction transmission system couples intensely with the vehicle and track through the suspension system, gear meshing and wheel-rail interaction. Under abnormal or failure conditions of the traction transmission system and wheelset, the service performance degrades and the safety of the train is compromised [2]. Therefore, investigating the dynamic responses of the motor car by focusing on the vibration characteristics of the gear transmission system and wheelset, especially the coupling effects between them, is essential and meaningful.

From the independent studies on trains and tracks to vehicle-track coupled dynamics, the dynamic performance of trailer cars for high-speed trains has been researched by many authors. Garg and Dukkipati [3] and Wickens [4] studied the dynamic characteristics of a vehicle system, but they neglected the coupling effects of track systems. The wheel-rail interaction becomes more intense with increasing running speed, so it is better to consider the whole system using a wheel-rail dynamic interaction model [5]. Based on those theory, the vehicle-track coupled dynamics has been widely investigated, including studies by Zhai et al. [6-8], and Nielsen and Igeland [9]. In the aforementioned dynamics model, the vehicle components are regarded as rigid bodies. As the key component of a railway vehicle, the flexible deformation of the wheelsets has been considered in many studies [10-13]. Flexible deformation should not be neglected under the impact of wheelrail forces, particularly at high speeds [10]. Lieh and Yin [12], and Ahmed and Sankar [13] investigated the effects of flexible deformation on a wheelset's hunting stability. In addition, the vehicle-track coupled dynamics model considering flexible wheelsets has been used to predict rail corrugations [14-17]. The wheel-rail longitudinal and lateral contact forces are increased 
significantly by the flexible deformation of the wheelset [10]. However, the aforementioned research focused mostly on the dynamic responses of the trailer cars, which could not provide a power transfer path from the traction motor to the wheelset because of the absence of a gear transmission system.

Owing to many advantages such as its simple structure, high transmission accuracy and easy maintenance, the gear transmission system is widely used in aerospace, automobile and railway vehicles. Many studies on gear transmission systems have been carried out, such as those of Kahraman and Singh [18], Kahraman [19], Benton and Seireg [20,21] and Blankenship and Singh $[22,23]$. However, the gear transmission system is simplified to a significant degree in those studies. Using basic theory, the dynamic performance of the gear transmission system itself has been investigated more comprehensively regarding gear failure [24,25], wear [26,27] and tooth profile $[28,29]$. As one of the most common gear mounting errors, geometric eccentricity has been studied by many researchers [30-33]. For example, Zhang et al. [31] investigated the steady-state responses of a gear system, considering gear eccentricity and static transmission error. Yu et al. [32] studied the dynamic coupling behaviour of a gear system with consideration of the helical angle, gear profile error and gear eccentricities. Xiang et al. [33] established the coupled torsion-bending vibration responses of a gear-rotor-bearing system to investigate coupling dynamics behaviours under the effects of gear eccentricity and rotational speed. Those studies indicate that gear eccentricity has a significantly influence on the transmission system [31-33]. However, research on the dynamic performance of the railway vehicle gear transmission system, considering gear eccentricity for the locomotive and motor car of a high-speed train, is relatively scarce.

Yao et al. [34] investigated the lateral stability of a locomotive-driven system using a single wheelset-driven system model. Huang et al. [35] established the multi-body system dynamics model of a motor car for a high-speed train to investigate the effect of gear meshing on vehicle dynamic performance. Wang [2] established a rigid-flexible multi-body dynamics model, considering the flexible deformation of the gearbox housing, to investigate the effects of wheel polygonal wear on the gearbox housing. Chen et al. [36,37] studied the coupling effects of a gear transmission system on the locomotive and track system using a vertical vehicle-track coupled dynamics model. Wang et al. [3840] established a three-dimensional motor car-track coupled dynamics model, considering the gear transmission system, and gave a detailed analysis of the vibration responses of the wheelsets and axle box bearings in a coupling vibration environment. Those studies show that the wheelset and wheel-rail interaction are influenced significantly by the gear transmission system and that the vibration of the wheelset directly affects the dynamic responses of the gear transmission system. However, the wheelset is regarded as a rigid body and the gear transmission is simplified as a pure torsional vibration system in those dynamics models [36-39]. The coupling effects of gear mesh excitations, nonlinear gear tooth backlash and the flexible deformation of the wheelset are usually neglected in the most of the literature. In general, the coupled torsion-bending dynamic performance of a transmission system with gear eccentricities for a high-speed train has not yet been reported.

Consequently, the main objective of this paper is to investigate the dynamic performance of the gear transmission system in a vehicle-track coupled system and to analyse the effects of gear eccentricity on the coupled system. In order to achieve this, a novel motor car-track coupled dynamics model is proposed with consideration of the dynamic interactions between the gear transmission system and flexible wheelset with time-varying mesh stiffness, backlash and wheel-rail nonlinear interaction. Then, comparisons between the previous works [39] and simulation results are implemented to validate the proposed dynamics model. Based on this model, the coupling relationship between the gears and flexible wheelset vibration is investigated by analysing the effects of gear eccentricity during the vehicle acceleration process.

\section{Motor Car-Track Coupled Dynamics Model with Flexible Wheelset}

A high-speed train consists of motor cars and trailer cars, which are driven on a track by the motors of the motor car through wheel-rail longitudinal creep forces, which overcome resistance forces such as friction and aerodynamic resistance, especially at high speeds. In this section, a motor car-track coupled dynamics model with flexible wheelsets is introduced based on the classical vehicle-track coupled dynamics model described in references [6,7]. This coupled dynamics model is shown in Figure 1 and Figure 2, in which the systems consist of vehicle, track and gear transmission subsystems. Those three subsystems are integrated into one dynamic system using suspension elements, gear meshing and wheel-rail dynamic interaction. 


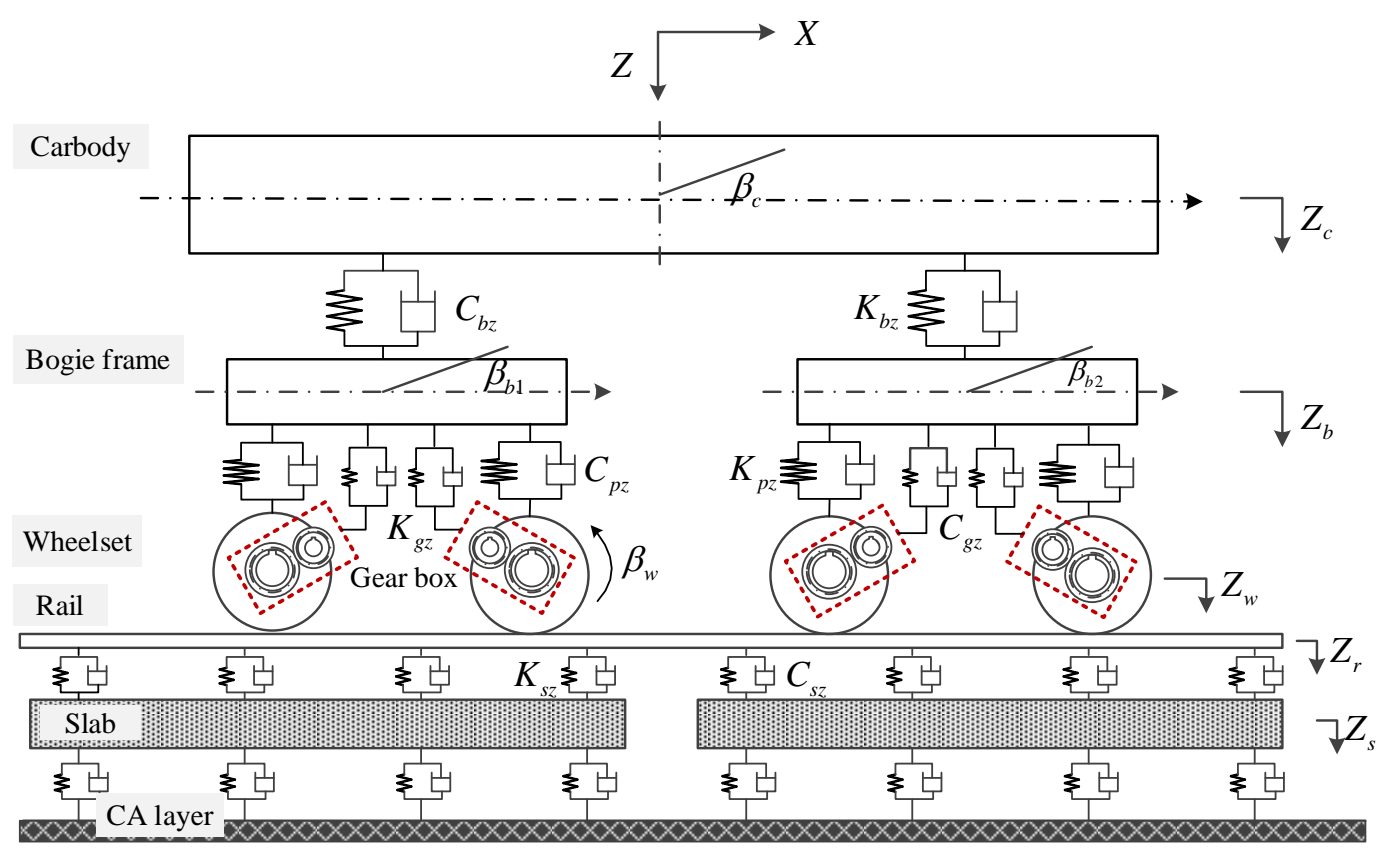

Figure 1 Motor car-track coupled dynamics model (elevation view).

\subsection{Motor Car Subsystem}

The motor car of a high-speed train comprises a car body, bogie frames, traction motors, gear transmission systems and flexible wheelsets, as shown in Figure 1 and 2. The rigid car body is supported on the two bogies through secondary suspension systems, where nonlinear elements such as the yaw damper and lateral stopper employed in [39] are adopted. The bogie is supported by two wheelsets through the primary suspension system, which comprises spring-damper elements (see Figure 1). The motors are mounted on the bogie frame through the flexible suspension system. One end of the gearbox housing is suspended on the bogie frame; the other end is mounted to the wheelset directly through the bearings, as shown in Figure 2. The suspension connections and flexible joints between various components of the motor car are achieved using spring-damper elements.

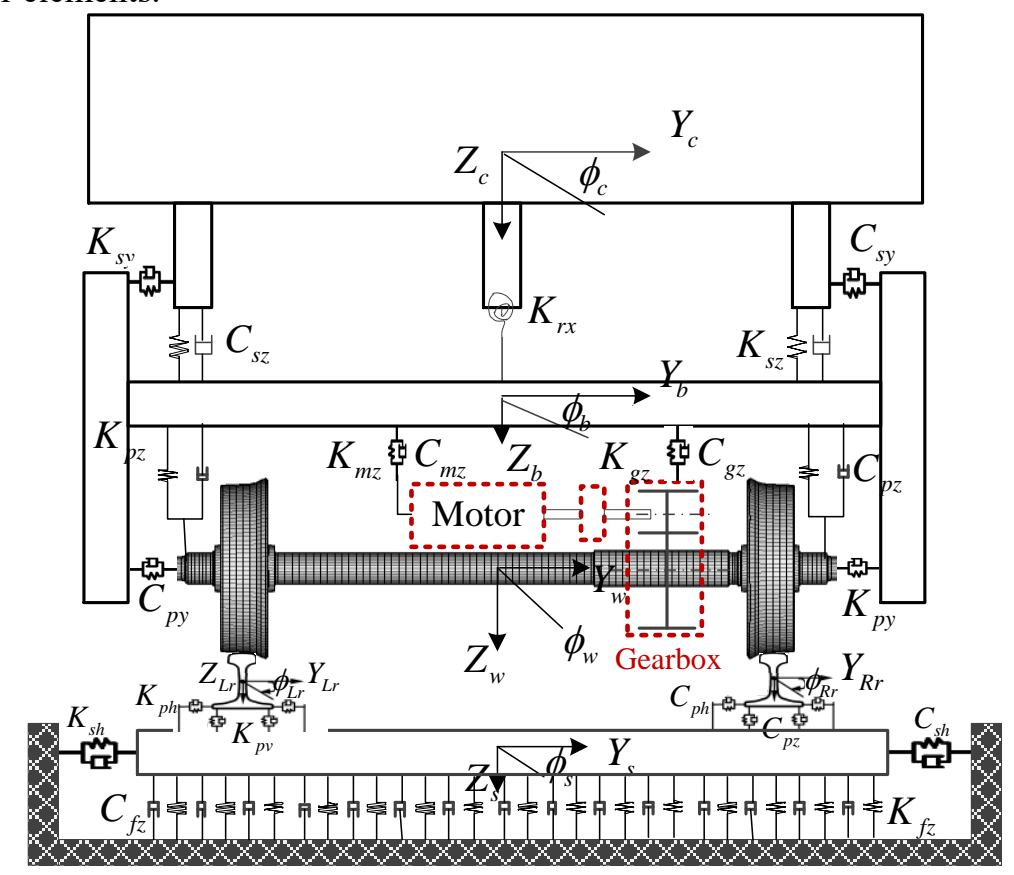

Figure 2 Motor car-track coupled dynamics model (side view).

The motor bogie of a typical high-speed train and its sketch map is shown as Figure 3. The 
traction transmission system is consisted of traction motor, flexible coupling, gearbox and wheelset. As shown in Figure 3 (b), the traction torque is generated by motor, and delivered to the pinion through a flexible coupling which is considered as a torsional spring-damper element. The pinion and gear wheel are mounted on the gearbox housing and wheelset respectively, which is simplified as a torsional vibration model coupling by gear meshing with time-varying mesh stiffness, nonlinear backlash, etc. The parameters of the gear pair are listed in Table 1. Vibrations of the gearbox housing are also considered, which takes into account the coupling effects between those vibrations and the torsional motion of the gear pair. It should be noted that all of the components of the motor car except for the wheelset are regarded as rigid bodies. The DOFs and symbols of the vehicle components are given in Table 2. The wheelset is described in the section 'Flexible wheelset model'.

Table 1 The parameters of the gear pair adopted in the model

\begin{tabular}{lll}
\hline Parameters & Pinion & Gear wheel \\
\hline Module & $6 \mathrm{~mm}$ & \\
Number of teeth & 35 & 85 \\
Face width & $65 \mathrm{~mm}$ & \\
Center distance & $380 \mathrm{~mm}$ & \\
Pressure angle & $20^{\circ}$ & \\
Transmission ratio & 2.428 & \\
\hline
\end{tabular}

Table 2 DOFs of the vehicle dynamics model

\begin{tabular}{lllllll}
\hline Vehicle component & Longitudinal & Lateral & Vertical & Roll & Pitch & Yaw \\
\hline Car body & $X_{\mathrm{c}}$ & $Y_{\mathrm{c}}$ & $Z_{\mathrm{c}}$ & $\phi_{\mathrm{c}}$ & $\beta_{\mathrm{c}}$ & $\psi_{\mathrm{c}}$ \\
Bogie frame $(i=1,2)$ & $X_{\mathrm{b} i}$ & $Y_{\mathrm{b} i}$ & $Z_{\mathrm{b} i}$ & $\phi_{\mathrm{b} i}$ & $\beta_{\mathrm{b} i}$ & $\psi_{\mathrm{b} i}$ \\
Motor $(i=1-4)$ & $X_{\mathrm{m} i}$ & $Y_{\mathrm{m} i}$ & $Z_{\mathrm{m} i}$ & - & $\beta_{\mathrm{m} i}$ & - \\
Gearbox $(i=1-4)$ & $X_{\mathrm{gh} i}$ & $Y_{\mathrm{gh} i}$ & $Z_{\mathrm{gh} i}$ & - & $\beta_{\mathrm{gh} i}$ & - \\
Pinion $(i=1-4)$ & - & $Y_{\mathrm{p} i}$ & $Z_{\mathrm{p} i}$ & $\phi_{\mathrm{p} i}$ & $\beta_{\mathrm{p} i}$ & - \\
Wheelset $(i=1-4)$ & $X_{\mathrm{w} i}$ & $Y_{\mathrm{w} i}$ & $Z_{\mathrm{w} i}$ & $\phi_{\mathrm{w} i}$ & $\beta_{\mathrm{w} i}$ & $\psi_{\mathrm{w} i}$ \\
\hline
\end{tabular}

(a)

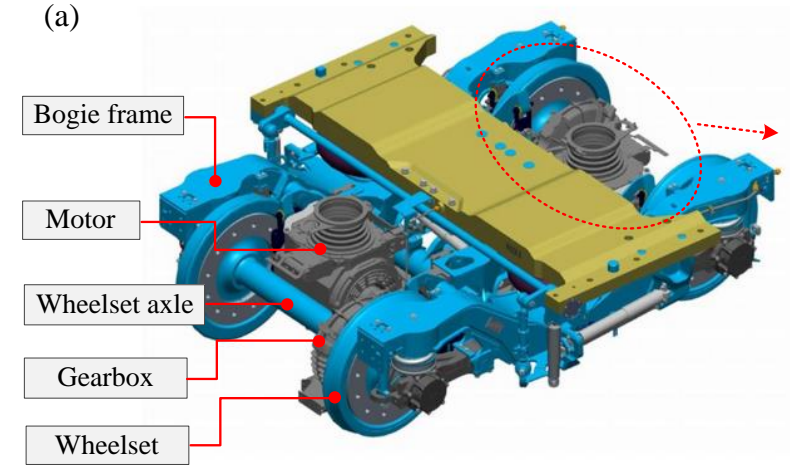

(b) Bogie frame

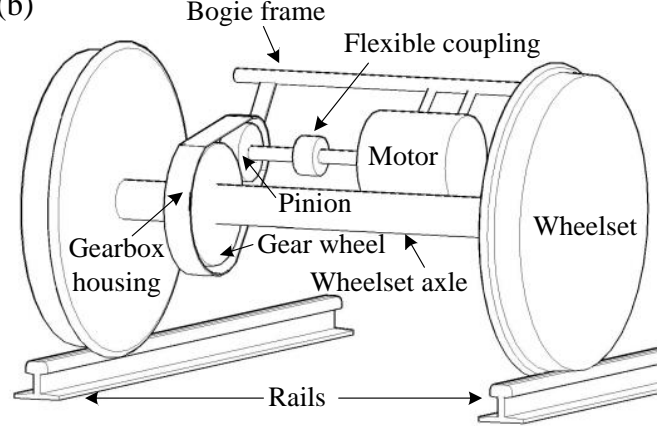

Figure 3 The motor bogie (a) and its sketch map (b) of a typical high-speed train in China.

The dynamics model of the gear transmission system with eccentricity for a high-speed train is illustrated in Figure 4. Therefore, the dynamic mesh force in the lateral direction $F_{y}$ and vertical direction $F_{z}$ can be obtained by ${ }^{[41]}$

$$
\begin{gathered}
F_{\text {meshy }}=\sin \beta\left\{k_{m}\left[y_{p}-\tan \beta\left(Z_{p}+\omega_{p} t r_{p}+\beta_{p} r_{p}+e_{p} \sin \beta_{p}+Z_{g h}\right)\right]\right. \\
-k_{m}\left[y_{g}-\tan \beta\left(Z_{g}-\omega_{g} t r_{g}-\beta_{g} r_{g}-e_{g} \sin \beta_{g}\right)\right] \\
+c_{m}\left[\dot{y}_{p}-\tan \beta\left(\dot{Z}_{p}+\omega_{p} r_{p}+\dot{\beta}_{p} r_{p}+e_{p} \dot{\beta}_{p} \cos \beta_{p}+\dot{Z}_{g h}\right)\right] \\
\left.-c_{m}\left[\dot{y}_{g}-\tan \beta\left(\dot{Z}_{g}-\omega_{g} t r_{g}-\dot{\beta}_{g} r_{g}-e_{g} \dot{\beta}_{g} \cos \beta_{g}\right)\right]\right\} \\
F_{\text {meshz }}=\cos \beta\left[k_{m}\left(Z_{p}+\beta_{p} r_{p}+\omega_{p} r_{p} t+e_{p} \sin \beta_{p}+Z_{g h}+Z_{g}-\beta_{g} r_{g}-\omega_{g} r_{g} t-e_{g} \sin \beta_{g}\right)\right. \\
\left.+c_{m}\left(\dot{Z}_{p}+\dot{\beta}_{p} r_{p}+\omega_{p} r_{p}+e_{p} \dot{\beta}_{p} \cos \beta_{p}+\dot{Z}_{g h}+\dot{Z}_{g}-\dot{\beta}_{g} r_{g}-\omega_{g} r_{g}-e_{g} \beta_{\dot{g}} \cos \beta_{g}\right)\right]
\end{gathered}
$$


where $k_{m}$ is the time-varying mesh stiffness, $c_{m}$ is the damping coefficient; $e_{p}$ and $e_{g}$ are the eccentricities of the pinion and gear wheel, respectively; $\beta$ is the helical angle of the gear pair; $r_{p}$ and $r_{g}$ presents the base circle radii of the pinion and gear wheel. $\omega_{p}$ and $\omega_{g}$ are the angular velocity of pinion and gear wheel; and $t$ is the simulation time. Because the motion equations of the pinion are similar to those in a previous work [39], they are not given here. It should be noted that the inertia forces of the pinion and gear wheel in the vertical direction, represented by $W_{p z}$ and $W_{g z}$, are considered in the motion equations as [32]

$$
\left\{\begin{array}{l}
W_{p z}=m_{p} e_{p} \ddot{\beta}_{p} \cos \beta_{p}+m_{p} e_{p}\left(\omega_{p}+\dot{\beta}_{p}\right)^{2} \sin \beta_{p} \\
W_{g z}=m_{g} e_{g} \ddot{\beta}_{g} \cos \beta_{g}+m_{g} e_{g}\left(\omega_{g}+\dot{\beta}_{g}\right)^{2} \sin \beta_{g}
\end{array}\right.
$$

where $m_{p}$ and $m_{g}$ are the mass of the pinion and gear wheel. According to the gear wheel is mounted directly on the flexible wheelset, the corresponding dynamic forces acting on the gear wheel are considered in the equations for the wheelset.

The interaction forces between the various components of motor cars and their motion equations are introduced in detail in previous works $[38,39]$, which are not given here. The motions of the motor car subsystem can be described by second-order differential equations, in the form of matrices, as

$$
\mathbf{M}_{\mathrm{V}} \ddot{\mathbf{X}}_{\mathrm{V}}+\mathbf{C}_{\mathrm{V}} \dot{\mathbf{X}}_{\mathrm{V}}+\mathbf{K}_{\mathrm{V}} \mathbf{X}_{\mathrm{V}}=\mathbf{F}_{\mathrm{RW}}+\mathbf{F}_{\mathrm{EXT}}
$$

where $\mathbf{M}_{\mathbf{v}}$ is the mass matrix of the motor car; $\mathbf{C}_{\mathbf{v}}$ and $\mathbf{K}_{\mathbf{v}}$ are the damping and stiffness matrices of the vehicle subsystem, respectively; $\mathbf{X}_{\mathrm{V}}, \dot{\mathbf{X}}_{\mathrm{v}}$ and $\ddot{\mathbf{X}}_{\mathrm{v}}$ are the displacement, velocity and acceleration vectors of the motor car components, respectively; and $\mathbf{F}_{\mathrm{RW}}$ and $\mathbf{F}_{\mathrm{EXT}}$ are the nonlinear wheel-rail contact forces and external forces, respectively.

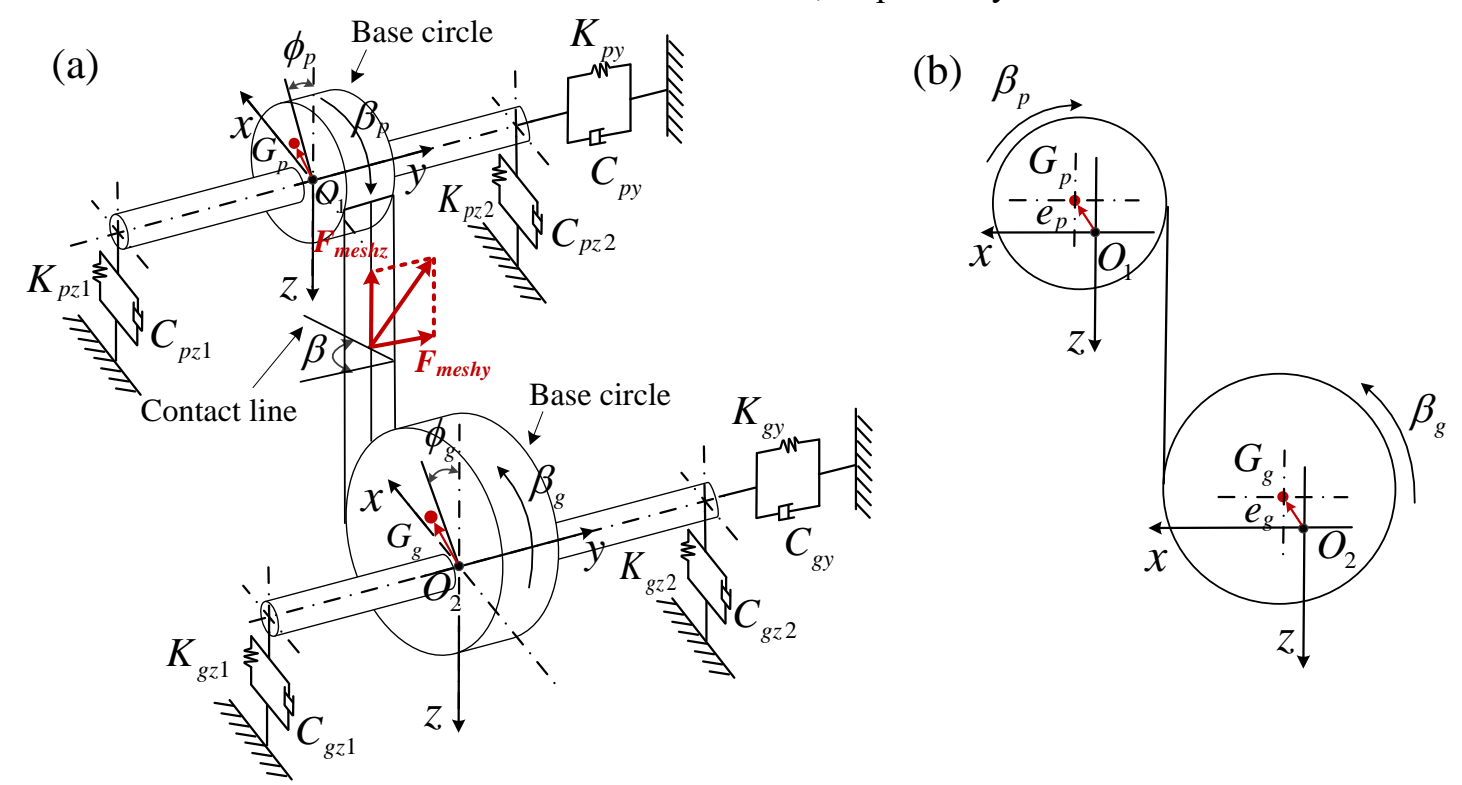

Figure 4 Gear transmission system dynamics model of a motor car for a high-speed train.

\subsection{Track model and wheel-rail interaction}

A typical slab track structure is employed to model the slab track subsystem that is widely used in the high-speed railway lines of China, as shown in Figures 1 and 2. The rail is modelled as Timoshenko beams with the vertical, lateral and torsional motions, which are supported by slabs. Using the modal superposition method, the governing equations of the rails, providing the lateral, vertical and torsional vibration are given as Eqs. (5), (6) and (7), respectively [42,43].

Lateral vibration: 


$$
\left\{\begin{array}{l}
\ddot{q}_{y k}+\frac{\kappa_{y} G A}{m}\left(\frac{k \pi}{l}\right)^{2} q_{y k}(t)+\kappa_{y} G A \frac{k \pi}{l} \sqrt{\frac{1}{m \rho I_{y}} \omega_{y k}(t)}=-\sum_{i=1}^{N_{\mathrm{s}}} F_{\mathrm{sy} i} Y_{k}\left(x_{\mathrm{s} i}\right)+\sum_{j=1}^{N_{\mathrm{w}}} F_{\mathrm{w} y j} Y_{k}\left(x_{\mathrm{w} j}\right) \\
\ddot{\omega}_{y k}(t)+\left[\frac{\kappa_{y} G A}{\rho I_{z}}+\frac{E I_{z}}{\rho I_{z}}\left(\frac{k \pi}{l}\right)^{2}\right] \omega_{y k}(t)-\kappa_{y} G A \frac{k \pi}{l} \sqrt{\frac{1}{m \rho I_{z}}} q_{y k}(t)=0
\end{array}\right.
$$

Vertical vibration:

$$
\left\{\begin{array}{l}
\ddot{q}_{z k}(t)+\frac{\kappa_{z} G A}{m}\left(\frac{k \pi}{l}\right)^{2} q_{z k}(t)-\kappa_{z} G A \frac{k \pi}{l} \sqrt{\frac{1}{m \rho I_{y}}} w_{z}(t)=\left[-\sum_{i=1}^{N_{\mathrm{s}}} F_{\mathrm{s} z i} Z_{k}\left(x_{\mathrm{s} i}\right)+\sum_{j=1}^{N_{\mathrm{w}}} F_{\mathrm{w} z j} Z_{k}\left(x_{\mathrm{w} j}\right)\right] \\
\ddot{\omega}_{z k}(t)+\left[\frac{\kappa_{z} G A}{\rho I_{y}}+\frac{E I_{y}}{\rho I_{y}}\left(\frac{k \pi}{l}\right)^{2}\right] \omega_{z}(t)-\kappa_{z} G A \frac{k \pi}{l} \sqrt{\frac{1}{m \rho I_{y}}} q_{z}(t)=0
\end{array}\right.
$$

Torsional vibration:

$$
\ddot{q}_{\mathrm{T} k}(t)+\frac{G K}{\rho I_{0}}\left(\frac{k \pi}{l}\right) q_{\mathrm{T} k(t)}=-\sum_{i=1}^{N_{\mathrm{s}}} M_{\mathrm{s} z i}(t) T_{k}\left(x_{\mathrm{s} i}\right)+\sum_{j=1}^{N_{\mathrm{w}}} M_{\mathrm{w} z i} T_{k}\left(x_{\mathrm{w} i}\right)
$$

In Eqs. (5)-(7), $I_{y}$ and $I_{z}$ are the second moments of area around the y- and z-axes, where $q_{y k}$, $q_{z k}$ and $q_{\mathrm{T} k}$ are the generalised coordinates performing the rail lateral, vertical and torsional deformation, respectively; $\omega_{y k}$ and $\omega_{z k}$ are the generalised coordinates of the deflection curve of the rail with respect to the $z$ - and y-axes, respectively; $m$ is the rail mass per unit length; $\rho$ is the rail density; $G$ is the shear modulus; $E$ is Young's modulus; $A$ is the rail cross section; $l$ is the calculation length of the rail; $F_{\mathrm{syi}}$ and $F_{\mathrm{w} y j}$ are the lateral forces acting on the rail from the slab and wheelset, respectively; $x_{\mathrm{s} i}$ and $x_{\mathrm{w} j}$ are the longitudinal positions of slab $i$ and wheelset $j ; \quad N_{\mathrm{w}}$ and $N_{\mathrm{s}}$ are the number of wheels and slabs in the model, respectively; $F_{\mathrm{s} z i}$ and $F_{\mathrm{w} z j}$ are the vertical forces acting on the rail from the slab and wheelset, respectively; and $M_{\mathrm{s} z i}$ and $M_{\text {wzj }}$ are the moments acting on the rail from the slab and wheelset, respectively. The values of the track model parameters are discussed in previous research study [38].

The established three-dimensional slabs are described as elastic rectangular plates supported on a viscoelastic foundation. Because the lateral bending stiffness of the slab is very large, the mode of slab vibration in the lateral direction is considered rigid. In general, the final equations of the slabtrack sub-model are expressed in terms of the matrix form as [6]

$$
\mathbf{M}_{\mathrm{T}} \ddot{\mathbf{X}}_{\mathrm{T}}+\mathbf{C}_{\mathrm{T}} \dot{\mathbf{X}}_{\mathrm{T}}+\mathbf{K}_{\mathrm{T}} \mathbf{X}_{\mathrm{T}}=\mathbf{F}_{\mathrm{WR}}
$$

where $\mathbf{M}_{\mathrm{T}}, \mathbf{C}_{\mathrm{T}}$ and $\mathbf{K}_{\mathrm{T}}$ are the mass, damping and stiffness matrices of the slab-track system, respectively; $\mathbf{X}_{\mathrm{T}}$ is the generalised coordinate of the slab-track system; and $\mathbf{F}_{\mathrm{WR}}$ is the load acting on this subsystem through the wheel-rail interface.

Wheel-rail interaction is the essential element coupling the vehicle and track subsystems. The dynamic forces at the wheel-rail interface are complex, comprising the normal contact forces and tangential creep forces. The nonlinear Hertzian elastic contact theory described in [44] is applied to calculate the normal wheel-rail forces. As for the wheel-rail creep forces, the Shen-Hedrick-Elkins model [45] is used to make modifications because Kalker's linear creep theory [46] is limited to small creepage.

\subsection{Flexible wheelset model}

In the dynamics model, the flexible wheelset is developed based on the finite element method. The flexible wheelset modelling method from the literature [14] is applied in this paper. Therefore, only a brief introduction is given here. Two configurations, namely undeformed and deformed, are defined to provide the kinematics of the flexible wheelset. The undeformed configuration rotates with the wheelset, whereas the deformed configuration has flexibility and small, rigid solid displacements. $\mathbf{w}(\mathbf{u}, t)$ corresponds to the material point of the solid whose undeformed configuration is in the spatial point $\mathbf{u}$ at instant $t$. In the two configurations, the displacement field can be defined by

$$
\mathbf{r}=\mathbf{u}+\mathbf{w}(\mathbf{u}, t)
$$

where $\mathbf{u}$ is an Eulerian vector coordinate in a fixed coordinate frame, $\mathbf{w}$ is the displacement 
containing the flexibility and small rigid displacements, and $\mathbf{r}$ is the final position. The coordinate frame is chosen so that the spin rotation is in the second axle. The following matrices are defined as:

$$
\mathbf{J}=\left(\begin{array}{ccc}
0 & 0 & 1 \\
0 & 0 & 0 \\
-1 & 0 & 0
\end{array}\right) ; \quad \mathbf{E}=\left(\begin{array}{ccc}
1 & 0 & 0 \\
0 & 0 & 0 \\
0 & 0 & 1
\end{array}\right)
$$

The angular velocity is given by

$$
\tilde{\Omega}=\left(\begin{array}{lll}
0 & 0 & \Omega \\
0 & 0 & 0 \\
-\Omega & 0 & 0
\end{array}\right)=\Omega \mathbf{J} ; \quad \text { and } \tilde{\Omega} \tilde{\Omega}=-\Omega^{2} \mathbf{E}
$$

The velocity with the rigid wheelset spinning is

$$
\mathbf{v}=\left(\begin{array}{lll}
v_{1} & v_{2} & v_{3}
\end{array}\right)^{T}=\tilde{\Omega} \mathbf{u}=\Omega \mathbf{J} \mathbf{u}=\Omega \tilde{\mathbf{u}}
$$

where $\tilde{\mathbf{u}}=\left(\begin{array}{lll}u_{3} & 0 & -u_{1}\end{array}\right)^{T}$. Hence, the velocity of the particle can be calculated through the material derivative of $\mathbf{r}$ with respect to $t$, as follows:

$$
\frac{D \mathbf{r}}{D t}=\dot{\mathbf{r}}=\Omega \mathbf{J} \mathbf{u}+\dot{\mathbf{w}}+\Omega \sum_{i} \tilde{u}_{i} \frac{\partial w}{\partial u_{i}}
$$

Combined with the modal approach, the flexible deformation of the wheelset $\mathbf{w}(\mathbf{u}, t)$ can be obtained by

$$
\mathbf{w}(\mathbf{u}, t)=\boldsymbol{\Phi}(\mathbf{u}) \mathbf{q}(t)
$$

where the $\boldsymbol{\Phi}(\mathbf{u})$ is the mode shape function matrix of the wheelset. In addition, the kinetic energy result of the wheelset is calculated by

$$
\begin{aligned}
E_{k} & =\frac{1}{2} \int_{V o l} \rho \frac{D \mathbf{r}^{T}}{D t} \frac{D \mathbf{r}}{D t} d v \\
& =\frac{1}{2} \dot{q}^{T} \int_{V o l} \rho \Phi^{T} \Phi d v \dot{\mathbf{q}}+\frac{1}{2} \Omega^{2} \mathbf{q}^{T} \times \int_{V o l} \rho\left(\sum_{i} \tilde{u}_{i} \frac{\partial \Phi^{T}}{\partial u_{i}}\right)\left(\sum_{i} \tilde{u}_{i} \frac{\partial \Phi}{\partial u_{i}}\right) d v \mathbf{q}+\Omega \dot{\mathbf{q}}^{T} \int_{V o l} \rho \Phi^{T} \mathbf{J} \mathbf{u} d v \\
& =\Omega^{2} \mathbf{q}^{T} \int_{V o l} \rho\left(\sum_{i} \tilde{u}_{i} \frac{\partial \Phi^{T}}{\partial u_{i}}\right) \mathbf{J u} d v+\Omega \dot{\mathbf{q}}^{T} \times \int_{V o l} \rho \Phi^{T}\left(\sum_{i} \tilde{u}_{i} \frac{\partial \Phi}{\partial u_{i}}\right) d v \mathbf{q}
\end{aligned}
$$

Once the kinetic energy is known, based on the modal approach and Lagrange's theory, the motion equation is given as

$$
\ddot{\mathbf{q}}+2 \Omega \Phi_{F E}^{T} \mathbf{V} \Phi_{F E}+\left(\mathbf{D}+\Omega^{2} \Phi_{F E}^{T}(\mathbf{A}-\mathbf{C}) \Phi_{F E}\right) \mathbf{q}=\Omega^{2} \Phi_{F E}^{T} \mathbf{c}+Q
$$

where $\mathbf{q}$ is the generalised coordinate, $\Phi_{F E}$ is the mode shape function obtained by the finite element model, $\mathbf{V}$ is the centrifugal force caused by the Coriolis acceleration, $\mathbf{A}$ is the convective acceleration, $\mathbf{C}$ is the centrifugal force due to the solid deformation, $\mathbf{c}$ is the constant centrifugal force and $\mathbf{Q}$ is the generalised force. The flexible wheelset model based on the finite element method, shown in Figure 5, is integrated into the motor car-track coupled dynamics model. According to the study in [47],20 vibration modes of the wheelset are employed in the coupled dynamics model, the typical modes are illustrated as Figure 5. The wheelset parameters which has been used in the model analysis are given in Table 3.

Table 3 Parameters of the wheelset

\begin{tabular}{lll}
\hline Main parameters & values & unit \\
\hline Wheelset mass & 1627 & $\mathrm{~kg}$ \\
Radius & 0.46 & $\mathrm{~m}$ \\
Wheelset $\mathrm{I}_{x x}$ & 825 & $\mathrm{~kg}\left[\mathrm{~m}^{2}\right.$ \\
Wheelset $\mathrm{I}_{y y}$ & 132 & $\mathrm{~kg}\left[\mathrm{~m}^{2}\right.$ \\
Wheelset $\mathrm{I}_{z z}$ & 830 & $\mathrm{~kg}\left[\mathrm{~m}^{2}\right.$ \\
\hline
\end{tabular}



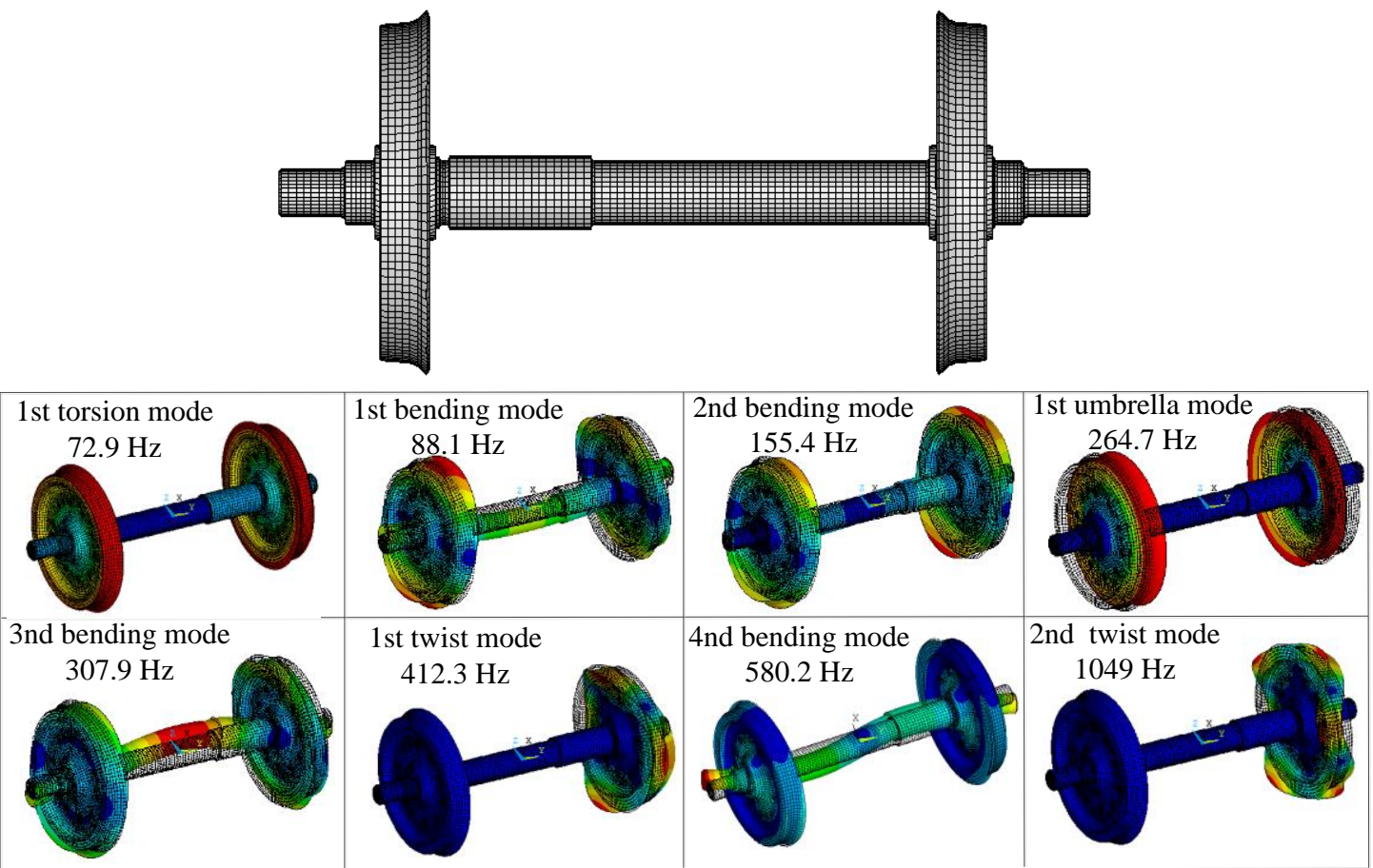

Figure 5 Finite element model of the motor car wheelset.

\section{Dynamic Simulation and Results Discussion}

In this section, the dynamic responses of the vehicle system are obtained using the proposed dynamics model excited by track irregularities. Additionally, the dynamic responses of the transmission system are measured from wheelset 1 of the motor car-track coupled dynamics model. The track irregularities of a high-speed train line in China explained in [38]. In addition, the traction torques and resistance forces according to the traction and resistance characteristics of a high-speed train [39] are applied to the motor rotor and wheelset to perform the power transmission from the motor rotor to the wheelset. To validate the dynamics model, the dynamic responses obtained with the flexible wheelset are compared to those obtained with a rigid wheelset, which is validated in a previous work [39]. Finally, the effects of gear eccentricity on the transmission system are investigated in detail.

\subsection{Responses comparison of the motor car with rigid and flexible wheelset}

The root mean square (RMS) values of the vibration acceleration obtained with the flexible wheelset are compared with those obtained using a rigid wheelset, whose dynamics model is validated in a previous work [39]. The RMS of vibration acceleration for the bogie frame and gearbox at various running speeds are illustrated in Figure 6 and Figure 7.

The RMS accelerations of the bogie frame in both the lateral and vertical directions increase with running speed, as shown in Figure 6. Also, the RMS acceleration of the bogie frame in the vertical direction is higher than that in the lateral direction. The lateral and vertical RMS acceleration values of the bogie frame are 0.40 and $0.71 \mathrm{~g}$, respectively, obtained with a rigid wheelset at a speed of $300 \mathrm{~km} / \mathrm{h}$, which is the common commercial running speed of high-speed trains in China. At that speed level, the RMS values of the lateral and vertical accelerations of the bogie frame obtained with the flexible wheelset are 0.38 and $0.73 \mathrm{~g}$, respectively. The results show that the RMS values of the bogie frame obtained with the rigid wheelset have little difference from those obtained with the flexible wheelset. This indicates that flexible deformation has little effect on the vibration of the bogie frame. 


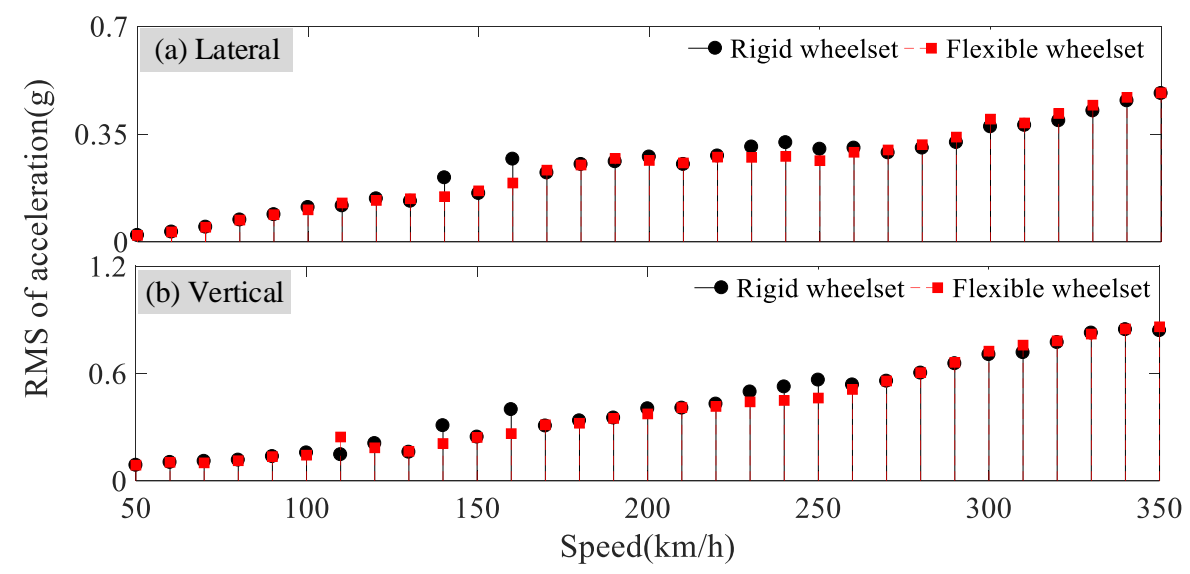

Figure 6 RMS values of vibration acceleration for the bogie frame in the (a) lateral and (b) vertical directions.

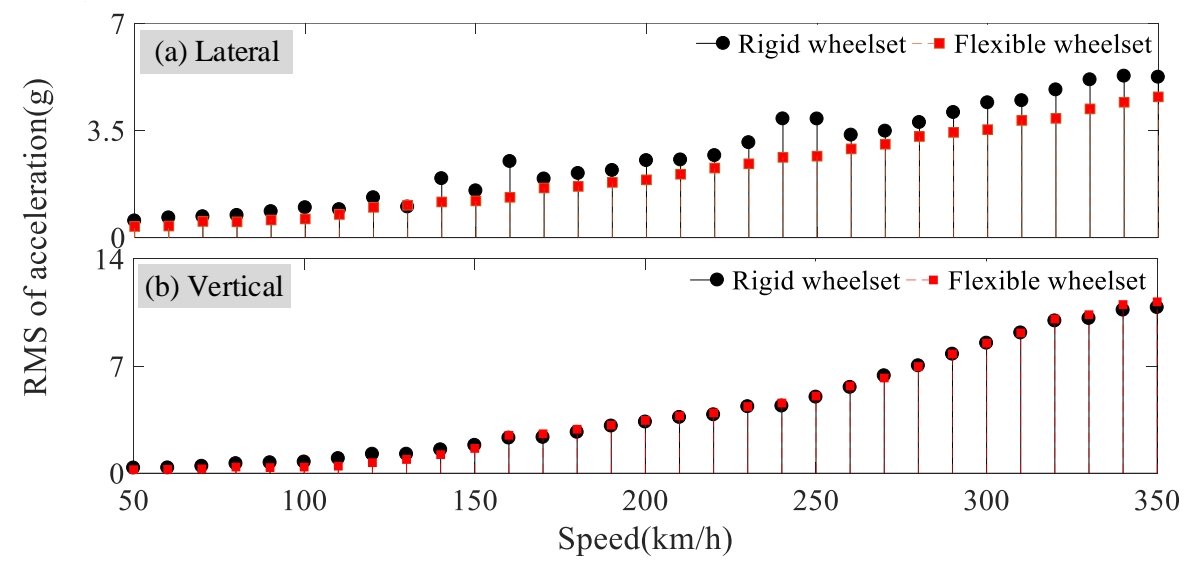

Figure 7 RMS values of vibration acceleration for the gearbox in the (a) lateral and (b) vertical directions.

Figure 7 shows the RMS acceleration of the gearbox obtained with rigid and flexible wheelsets at various running speeds. The RMS values of the gearbox change with running speed and show a similar tendency to that of the bogie frame. However, the RMS values of the gearbox are higher than those of the bogie frame, which indicates that the vibration is effectively attenuated from the wheelset to the bogie frame through the primary suspension system. As shown in Figure 7(a), the lateral acceleration RMS values of the gearbox obtained with the rigid wheelset are higher than those obtained with the flexible wheelset. In addition, the vertical RMS acceleration values of the gearbox obtained with the rigid wheelset are close to those obtained with the flexible wheelset. At a speed of $300 \mathrm{~km} / \mathrm{h}$, the lateral (vertical) vibration RMS acceleration values of the gearbox are $4.11 \mathrm{~g}(8.51 \mathrm{~g})$ and $3.63 \mathrm{~g}(8.49 \mathrm{~g})$ for the rigid and flexible wheelsets, respectively.

Figure 8 shows the wheel-rail forces responses at various speeds. The wheel-rail forces exhibit a similar tendency to the vibration acceleration, which increases with running speed. The longitudinal wheel-rail force obtained from the rigid wheelset is slightly higher than that on flexible wheelset, particularly at low running speed (Figure 8 (a)). As shown in Figure 8 (b), the RMS of the lateral wheel-rail force obtained with the rigid wheelset are higher than that using the flexible wheelset, which causes a higher lateral acceleration RMS of the gearbox, as shown in Figure 7(a). The RMS of the vertical wheel-rail force obtained with the rigid wheelset are little higher than that obtained with flexible wheelset. At a speed of $300 \mathrm{~km} / \mathrm{h}$, the dynamic wheel-rail forces in the time domain are illustrated in Figure 8 (c), (d) and (e). This shows that the rigid wheelset causes higher wheel-rail forces than the flexible wheelset, especially the lateral wheelrail forces.

Consequently, the wheelset flexible deformation has little effect on the vibration of the bogie frame. However, it has a non-negligible effect on the lateral wheel-rail forces, which cause differences in the lateral vibration of gearbox compared with the results obtained with the rigid wheelset. In general, the proposed dynamics model with the flexible wheelset is validated by comparing the dynamic responses obtained with the rigid wheelset. 

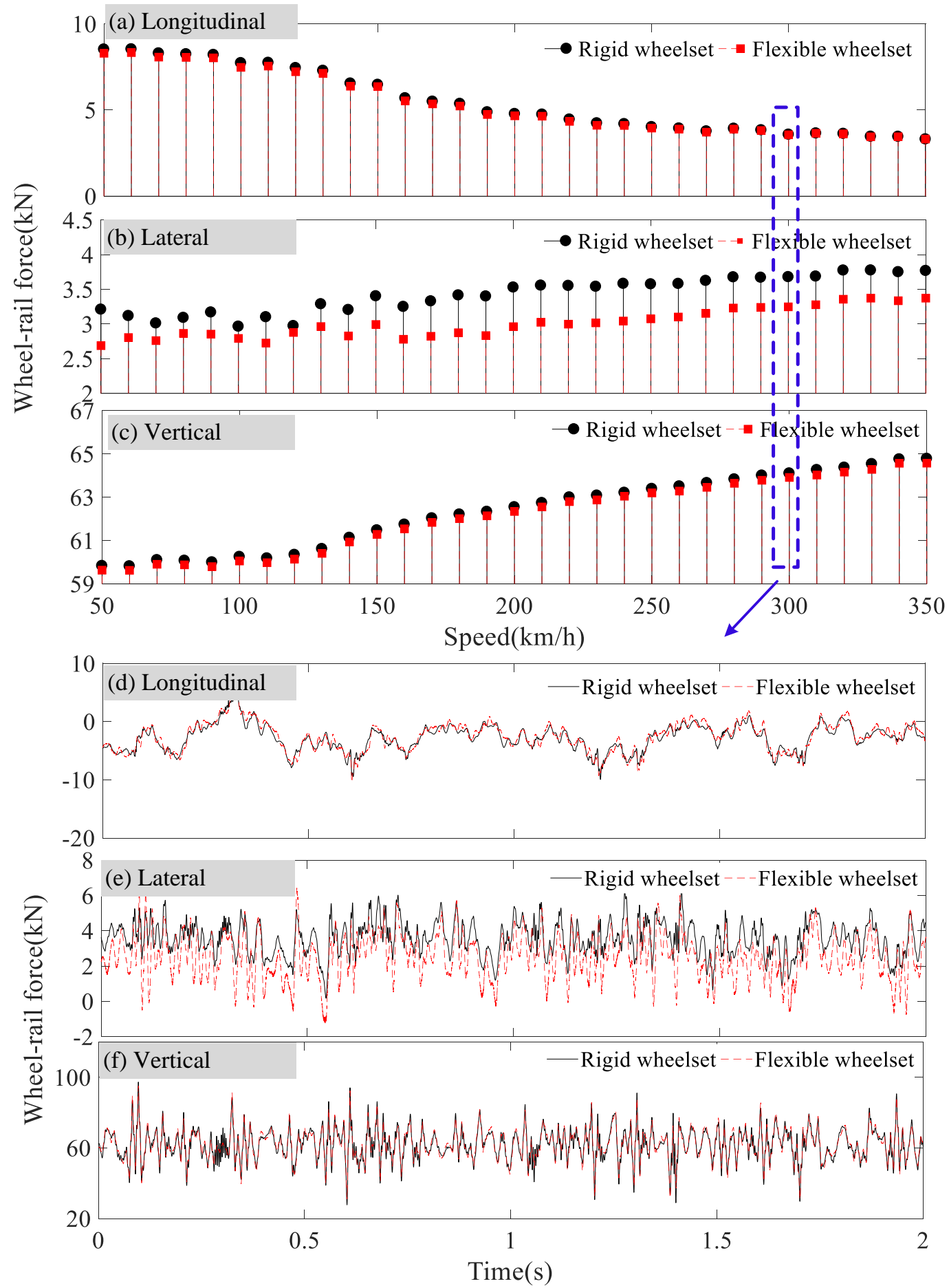

Figure 8 Wheel-rail dynamic forces: RMS values in the (a) longitudinal, (b) lateral and (c) vertical directions; and the time-domain waveform in the (a) longitudinal, (b) lateral and (c) vertical directions.

\subsection{RMS of vibration response with variable eccentricity during acceleration process}

The gear transmission of a high-speed train is a complicated system with strong nonlinearity and time variance. In addition, the flexible deformation of the wheelset is considered in the gear mesh procedure during vehicle operation. During the simulation, the traction torque employed in a previous work [39] is adopted. With the consideration of wheelset flexible deformation, the dynamic responses of the transmission system are obtained with pinion eccentricities at various speeds, as shown in Figure 9 and Figure 10. At the same time, the simulated results of this system 
under identical conditions using the rigid wheelset are also shown in Figure 9 and Figure 10.

Figure 9 (a) and (b) shows the RMS values of the DMF and LCF, respectively. The initials 'WS' mean wheelset, and ' $F$ ' and ' $R$ ' mean flexible and rigid, respectively. The amplitude of the pinion eccentricity is $100 \mu \mathrm{m}$. This shows that the DMF and LCF are decreasing with an increase in running speed, which is due to the decrease in traction torque. The RMS values of the DMF and LCF show little difference at low speeds. However, the RMS of DMF using the rigid wheelset are higher than those obtained with the flexible wheelset at high speeds $(>200 \mathrm{~km} / \mathrm{h})$. Meanwhile, the RMS values of the LCF using the flexible wheelset are higher than those obtained with the rigid wheelset. This phenomenon is caused by the flexible deformation of the wheelset induced by pinion eccentricity. The vibration of the pinion with the rigid wheelset is more violent than that obtained with the flexible wheelset at high speeds, as shown in Figure 10 (a). However, the flexible deformation of the wheelset contributes to the torsional vibration itself, especially at high speeds, which causes a higher LCF. The results indicate that wheelset flexible deformation has a non-negligible influence on the torsional vibration of the transmission system, especially at high speeds.

(a)

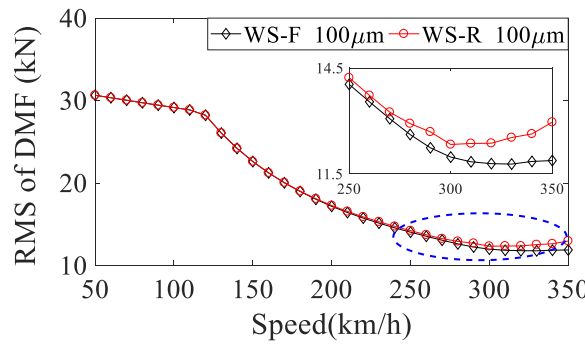

(b)

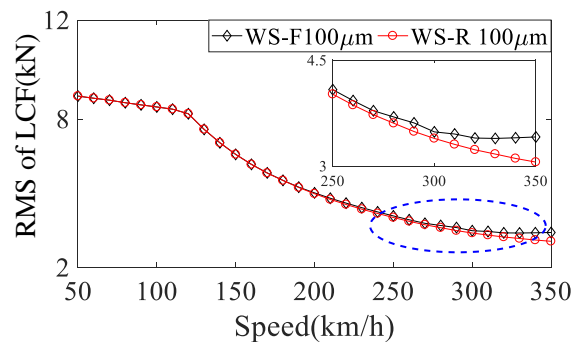

Figure 9 Comparison of the RMS of: (a) the DMF and (b) LCF with eccentricity for the rigid and flexible wheelsets.

(a)

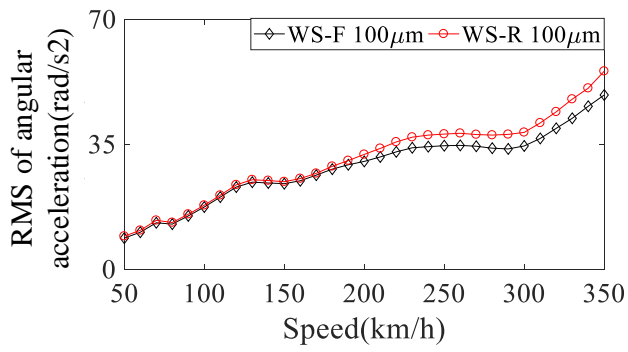

(b)

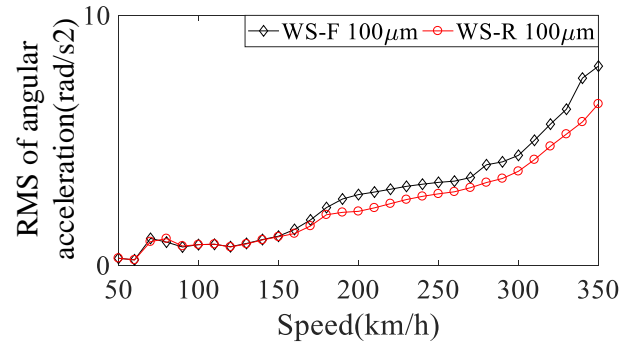

Figure 10 Comparison of the angular acceleration RMS of: (a) the pinion and (b) wheelset with eccentricity for the rigid and flexible wheelsets.

(a)

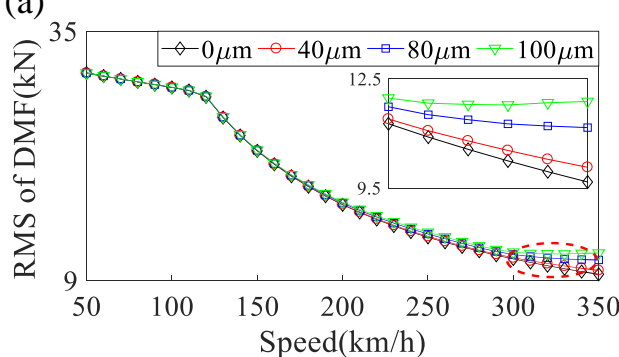

(b)

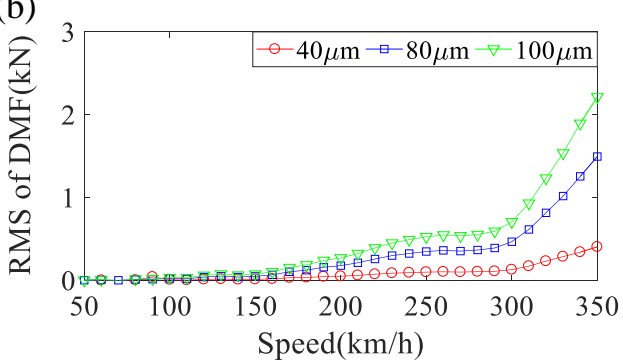

Figure 11 RMS of (a) the DMF with different eccentricity and (b) the DMF increment compared to that without eccentricity.

In order to study the effects of the amplitude of the pinion eccentricity on the transmission system, the RMS differences in the dynamic responses of the transmission system with changing eccentricities are simulated, as shown in Figure 11-Figure 13. The RMS values of the DMF and their increase compared to those without eccentricity are shown in Figure 11 (a) and (b). The figure shows that the amplitude of the gear eccentricity has little influence on the DMF at speeds below $200 \mathrm{~km} / \mathrm{h}$. Meanwhile, the eccentricity results in a significant increase in the DMF when the running speeds are higher than $300 \mathrm{~km} / \mathrm{h}$. In addition, the LCF shows a similar tendency to that of changes in the DMF with respect to running speed, as shown in Figure 12. It can be noticed that the RMS values of the DMF and LCF are decreasing with increasing running speed. However, the 
pinion eccentricity has non-negligible effect on the DMF and LCF at the commercial running speed of $300 \mathrm{~km} / \mathrm{h}$.

(a)

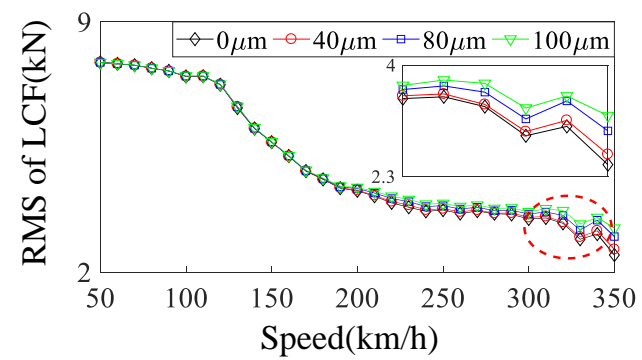

(b)

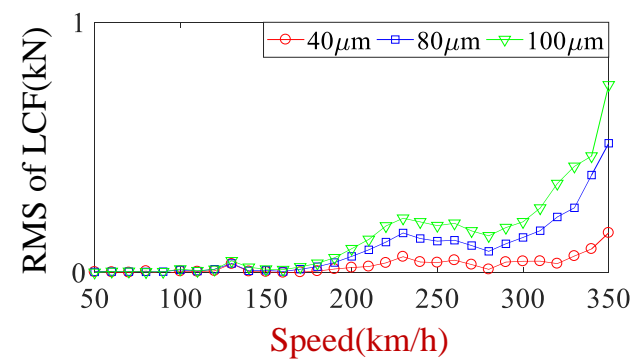

Figure 12 RMS of (a) the LCF with different eccentricity and (b) the LCF increment compared to that without eccentricity.

Unlike the DMF and LCF, the torsional vibration of the pinion and wheelset are increasing with running speed, as shown in Figure 13. Figure 13 shows that the torsional vibration amplitude of the pinion is clearly higher than that of the gear wheel because the gear wheel is fixed on the wheelset. It also shows that the eccentricity amplitude contributes significantly to the vibration at high speeds. The torsional vibration of the wheelsets has a similar tendency to that of the pinion and gear. Furthermore, the torsional vibration of the wheel near the gearbox is clearly higher than that of the wheel far from the gearbox, as shown in Figure 13 (c) and (d), which could not be reflected using the dynamics model with the rigid wheelset.

(a)
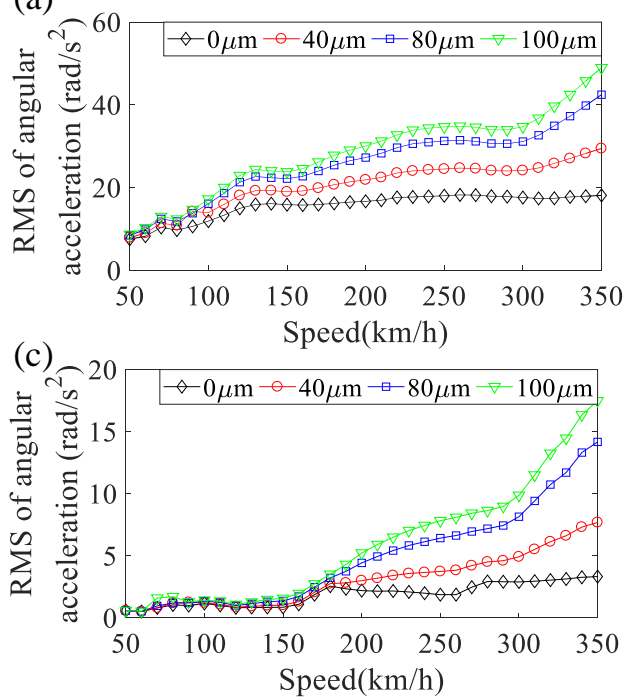

(b)

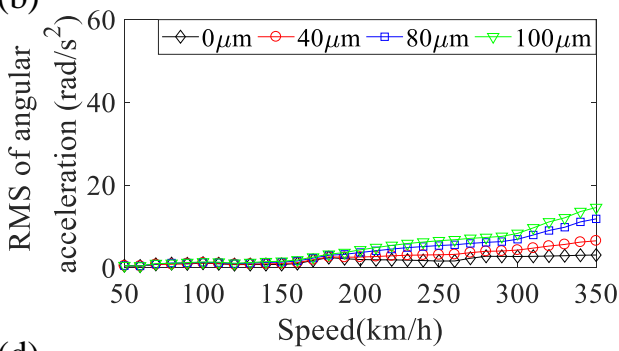

(d)

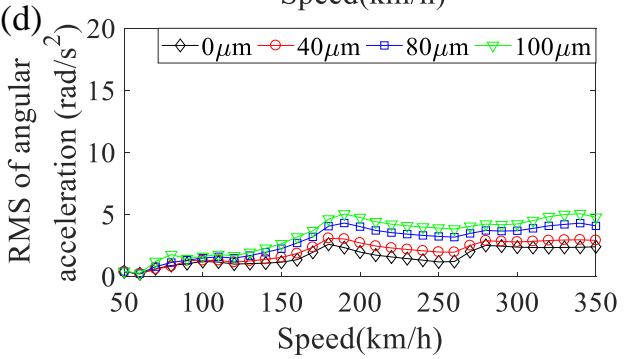

Figure 13 RMS values of angular acceleration: (a) pinion, (b) gear wheel, (c) left wheel and (d) right wheel.

\subsection{The time domain waveform and frequency domain responses with different eccentricity}

Figure 14 shows the dynamic responses of the traction transmission system with the pinion eccentricity at the speed of $300 \mathrm{~km} / \mathrm{h}$, and the amplitude of the pinion eccentricity is $100 \mu \mathrm{m}$. The dynamic mesh force (DMF) and wheel-rail longitudinal creep force (LCF) reveals a clearly periodicity with $0.014 \mathrm{~s}$ caused by the pinion eccentricity, which is the pinion rotation period at $300 \mathrm{~km} / \mathrm{h}$. Additionally, the amplitude of the dynamic meshing force obtained with rigid wheelset is greater than that obtained with flexible wheelset, as shown in Figure 14 (a). However, the flexible deformation of wheelset also contributes to a higher longitudinal creep force, as shown in Figure 14 (b). It indicates that the dynamic responses of traction transmission system are significantly influenced by the flexible deformation of wheelset with the consideration of the gear eccentricity. Hence, the flexible wheelset is adopted to investigate the effects of gear eccentricity on the transmission system below. 


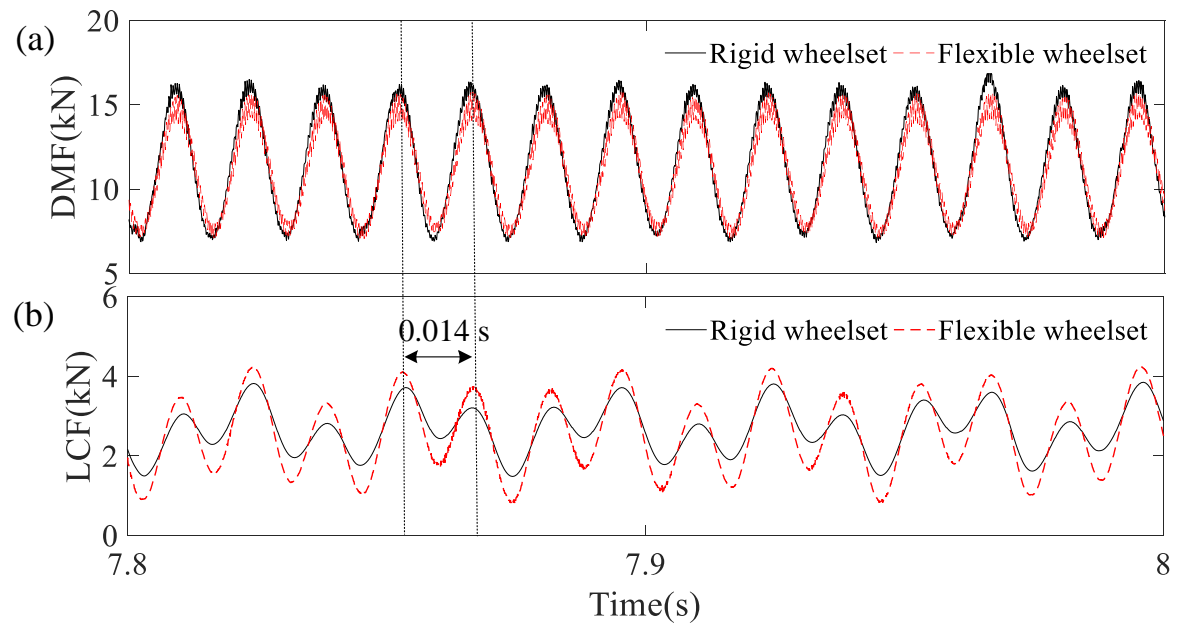

Figure 14 Time history of the (a) DMF and (b) LCF.

To further analyse the influence of eccentricity on the dynamic performance of the system, the responses are studied in the time domain waveform and frequency domain at the most common operating speed $(300 \mathrm{~km} / \mathrm{h})$. The results obtained with an eccentricity amplitude of $100 \mu \mathrm{m}$ for the pinion and gear wheel are given in Figure 15-Figure 19, respectively. To make a comparison, the responses without consideration of eccentricity are also given in those figures.

(a)

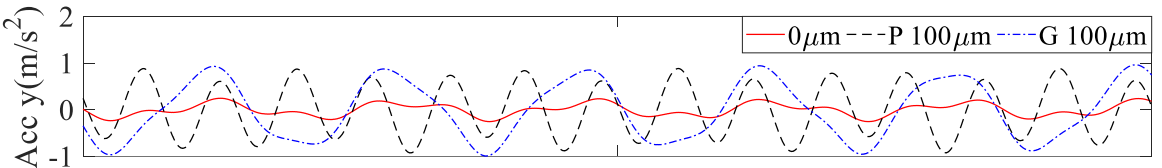

(b)

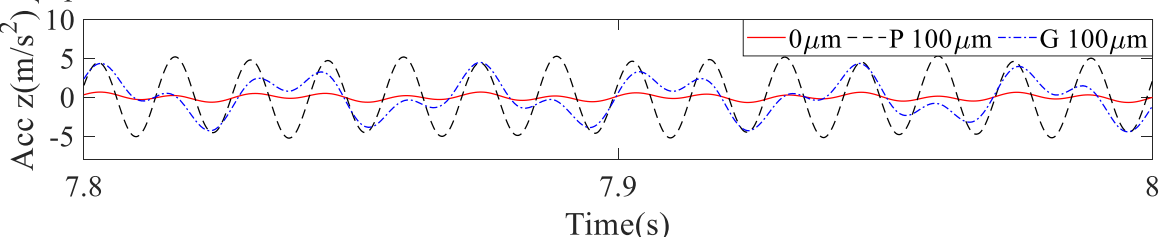

(c)

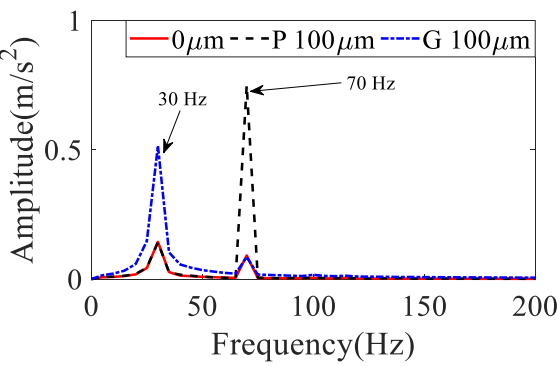

(d)

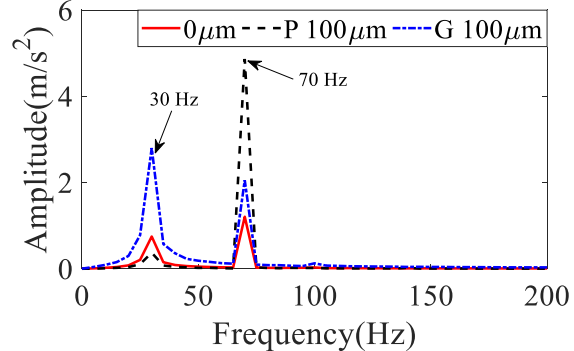

Figure 15 Dynamic responses of the bogie frame: time domain of the (a) lateral and (b) vertical accelerations; frequency domain of the (c) lateral and (d) vertical accelerations.

Figure 15 shows the time waveforms of bogie acceleration, which have the characteristics of periodic shock. In addition, the eccentricity of both the pinion and gear wheel contributes significantly to the vibration of the bogie frame in the lateral direction and especially in the vertical direction. As shown in Figure 15 (c) and (d), the vibration in the bogie frame consists basically of frequency components at the excitation frequencies of $30 \mathrm{~Hz}\left(f_{1}\right)$ and $70 \mathrm{~Hz}\left(f_{2}\right)$ caused by the gear wheel and pinion eccentricity. Because the pinion, gear wheel and wheelset exhibit similar dynamic characteristics, only the results of the pinion are illustrated in Figure 16. The vibrations of the pinion in the lateral and vertical directions show similar characteristics to those of the bogie frame. Furthermore, the lateral and vertical vibrations of the pinion are dominated mainly by some high-frequency components, whereas its torsional vibration is induced mainly by the eccentricity. When the system is excited by pinion eccentricity, the vibration frequencies include the $f_{2}, f_{m}($ mesh frequency $2451 \mathrm{~Hz}), f_{m} \mp f_{2}, 2 f_{m}$ and $2 f_{m} \mp f_{2}$, as shown in Figure 16 (d), (e) and (f). The $f_{1}, f_{m}, f_{m} \mp f_{1}, 2 f_{m}$ and $2 f_{m} \mp f_{1}$ frequencies appear when the gear wheel eccentricity occurs. The vibration characteristics of the wheelset and gear 
wheel has similar tendency with the pinion, and therefore neglected in this study.

The vibration of this system is induced by the dynamic forces caused by gear mesh, eccentricity and wheel-rail interaction. The dynamic force characteristics of this system in the time domain and frequency are illustrated in Figure 17 and Figure 18, respectively. It can be seen from Figure 17 that the eccentricity leads to increasing amplitude of the DMF and LCF. The maximum amplitude of the DMF and LCF are 17.7 and $4.9 \mathrm{kN}$ (left wheel), respectively, with an increase of $41.6 \%$ and $44.1 \%$ compared to those without pinion eccentricity. For the comparison without gear eccentricity, the peak value of the DMF and LCF are 16.6 and $4.3 \mathrm{kN}$ (left wheel), respectively, with an increase of $32.8 \%$ and $26.5 \%$ when gear eccentricity occurs during operation. It should be noted that the LCF of the left wheel fluctuates more violently than that of the right wheel because of the structural characteristics of the traction system and flexible deformation of the wheelset. The frequency results of the LCF are illustrated in Figure 18, which shows the frequency components of $f_{1}, f_{2}$ and $f_{m}$.

The vibrations of the pinion, gear wheel and wheelset are induced mainly by the DMF and exhibit a similar dynamic behaviour to the DMF. Therefore, the frequency results of the DMF at various speeds induced by the eccentricity are as shown in Figure 19. The amplitude of the DMF caused by the eccentricity is increasing with vehicle running speed. In addition, the pinion eccentricity has an obviously greater effect on the DMF than the gear wheel eccentricity, and the amplitudes show higher components at frequency $f_{2}$ than at $f_{1}$. The DMF also comprises the frequency components $f_{m}, 2 f_{m}, f_{m} \mp f_{1}$ (with gear eccentricity) and $f_{m} \mp f_{2}$ (with pinion eccentricity). Consequently, the eccentricity has a significant influence on the gear transmission system, especially the pinion eccentricity at high speeds.

(a)

(b)

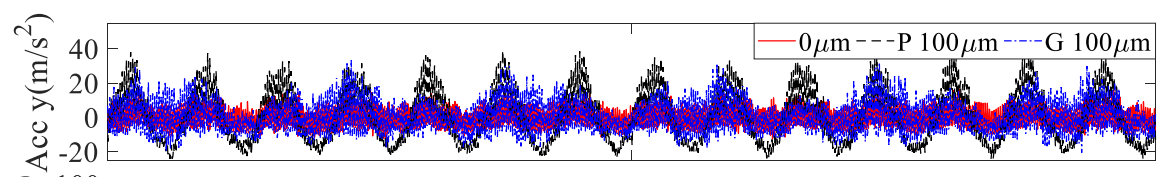

(b)

(c)
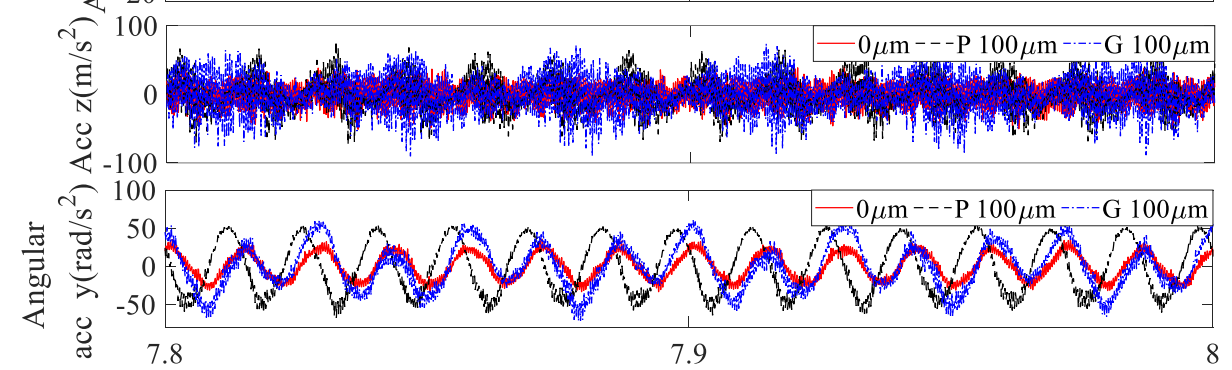

(d)
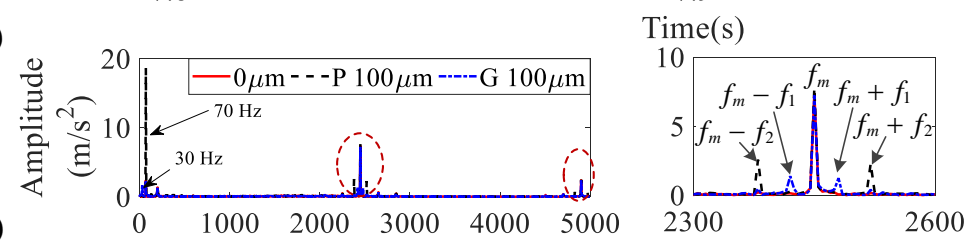

(e)

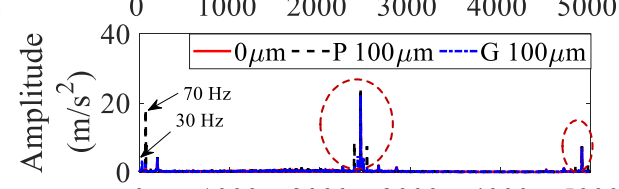

(f)
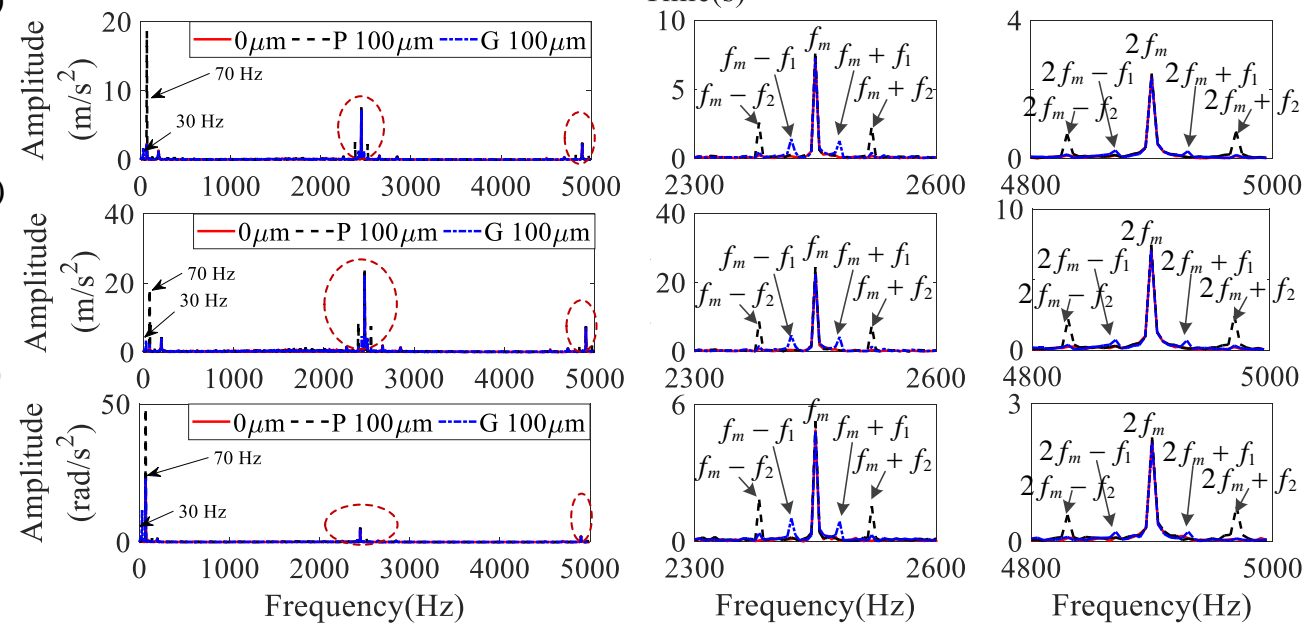

Figure 16 Dynamic responses of the pinion: time domain of the (a) lateral, (b)vertical and (c) angular accelerations; frequency domain of the (d) lateral, (e)vertical and (f) angular accelerations. 

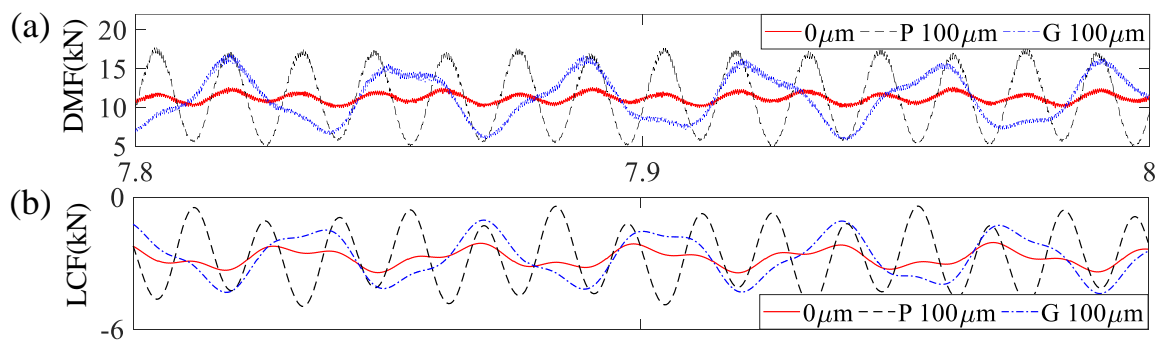

(c)

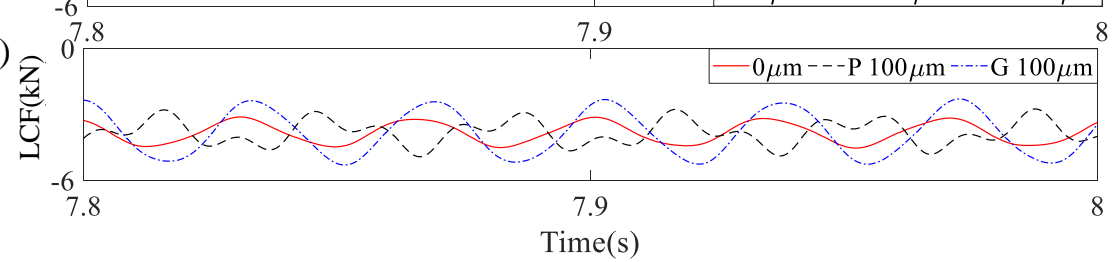

Figure 17 Dynamic forces of the system: (a) the DMF, (b) longitudinal creep force of the left wheel and (c) right wheel.
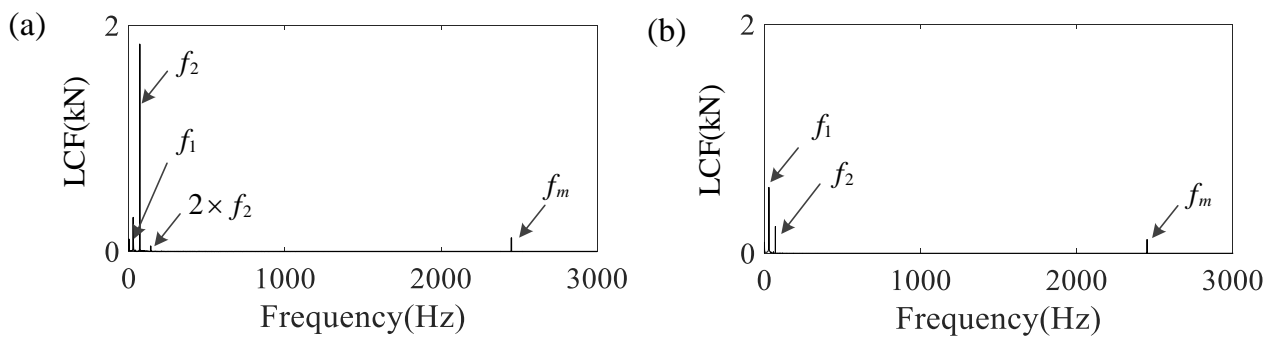

Figure 18 Responses of the LCF in the frequency domain with (a) pinion and (b) gear eccentricity.

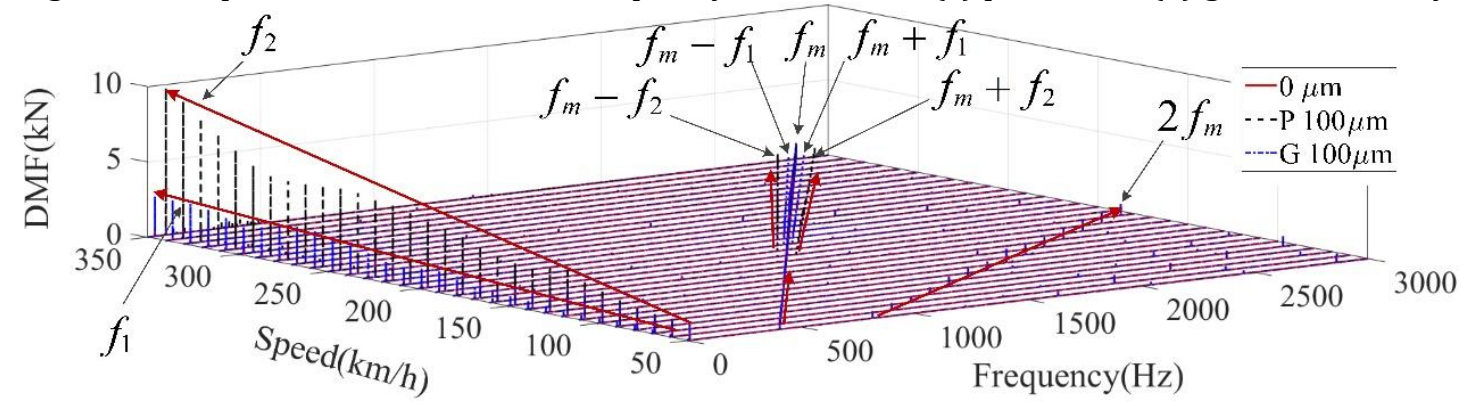

Figure 19 DMF results in the frequency domain with eccentricity at various speeds.

\section{Conclusion}

A nonlinear dynamics model of a vehicle-track coupled system was established in order to explore the coupled vibration of the transmission system for a high-speed train. The proposed model couples the movements of the transmission system and flexible wheelset in a vehicle-track vibration environment. It also enables the simulation of power transmission from the traction motor to the wheelset during the acceleration process. The dynamic responses with the flexible wheelset were compared to those obtained with a rigid wheelset to validate the proposed model. Based on the model, the dynamic performance of the transmission system under gear eccentricity during the vehicle acceleration process could be analysed and discussed.

The effects of eccentricity on the vibration responses and the coupling relationship between the gear pair and wheelset were comprehensively analysed in the vehicle-track vibration environment. The results revealed that the DMF and LCF were dominated mainly by the torque from the traction motor and decreased with running speed. Meanwhile, the torsional vibration of the transmission system became violent with the increase in operating speed. The influence of eccentricity on the torsional vibration of the system was obvious at high speeds. Furthermore, the increase in the DMF and LCF was influenced significantly by the eccentricity and became greater at running speeds over $300 \mathrm{~km} / \mathrm{h}$. The frequency components of the system consisted of the shaft frequency, gear mesh frequency and their modulation frequencies. In addition, the amplitudes of the vibration acceleration, DMF and LCF increased with increasing eccentricity, but other 
amplitudes had small changes. Hence, the eccentricity should be controlled within a reasonable range to avoid the instability phenomenon, especially at high speeds.

The torsional vibration of the wheel near the transmission system was more intense than the other wheel in the same wheelset. Furthermore, the LCFs of the various wheels of the wheelset are different during the vehicle acceleration process, which may cause a difference in wheel wear. Hence, the flexible deformation of the wheelset should not be neglected when assessing the dynamic performance of a traction system and analysing the wheel-rail interaction of a motor car.

\section{Acknowledgements}

The first author thanks the support of the China Scholarship Council.

\section{Funding}

The author(s) is grateful for the financial support provided by the National Key Research and Development Program of China (Grant No 2016YFB1200401-102A and 102B) and State Key Laboratory of Traction Power, Southwest Jiaotong University (No.2016 TPL_T04).

\section{Reference}

1. Wang ZW, Cheng Y, Mei GM, et al. Torsional vibration analysis of the gear transmission system of high-speed trains with wheel defects. Proc IMechE, Part F: J Rail and Rapid Transit 2019 DOI: 10.1177/0954409719833791.

2. Wang ZW, Mei GM, Zhang WH, et al. Effects of polygonal wear of wheels on the dynamic performance of the gearbox housing of a high-speed train. Proc IMechE, Part F: J Rail and Rapid Transit 2018. 232(6): 1852-1863.

3. Garg VK, Dukkipati RV. Dynamics of railway vehicle systems. Toronto: Academic Press; 1984 4. Wickens AH. Fundamentals of rail vehicle dynamics: guidance and stability. Lisse: Swets \& Zeitlinger; 2003.

5. Zhai WM, Sun X. A detailed model for investigating vertical interaction between railway vehicle and track. Veh Syst Dyn. 1994;23(S1):603-615.

6. Zhai WM,Wang KY, Cai CB. Fundamentals of vehicle-track coupled dynamics. Veh Syst Dyn. 2009;47(11):1349-1376.

7. ZhaiWM, Xia H, Cai CB, et al. High-speed train-track-bridge dynamic interactions - part I: theoretical model and numerical simulation. Int J Rail Transp. 2013;1(1-2):3-24.

8. Zhai WM,Wang SL, Zhang N, et al. High-speed train-track-bridge dynamic interactions part II: experimental validation and engineering application. Int J Rail Transp. 2013;1(1-2):25-41.

9. J. Nielsen, A. Igeland, Vertical dynamic interaction between train and track - influence of wheel and track imperfections, J. Sound Vib. 187 (5) (1995) 825-839.

10. Wu XW, Rakheja S, Ahmed A, et al. Influence of a flexible wheelset on the dynamic responses of a high-speed railway car due to a wheel flat. Proc IMechE, Part F: J Rail and Rapid Transit 2017; 232(4): 1033-1048.

11. Morys B. Enlargement of out-of-round wheel profiles on high speed trains. J Sound Vib 1999; 227: 965-978.

12. Lieh J and Yin J. Stability of a flexible wheelset for high speed rail vehicles with constant and varying parameters. J Vib Acoust 1998; 120: 997-1002.

13. Ahmed A and Sankar S. Lateral stability behavior of railway freight car system with elasto-damper coupled wheelset: Part 2- Truck model. J Mech Transm Autom Des 1987; 109: 500-507.

14. Casas JM, Mazzola L, Baeza L, Bruni S. Numerical estimation of stress in railway axles using a train-track interaction model. Int J Fatigue. 2013; 47:18-30.

15. Baeza L, Fayos J, Roda A, et al. High frequency railway vehicle-track dynamics through flexible rotating wheelsets. Veh Syst Dyn 2008; 46: 647-659.

16. Baeza L, Vila P, Xie G, et al. Prediction of rail corrugation using a rotating flexible wheelset coupled with a flexible track model and a non-Hertzian/non-steady contact model. J Sound Vib 2011; 330: 4493-4507.

17. Vila $\mathrm{P}$, Fayos $\mathrm{J}$ and Baeza L. Simulation of the evolution of rail corrugation using a rotating 
flexible wheelset model. Veh Syst Dyn 2011; 49(11): 1749-1769.

18. Kahraman A and Singh R. Interactions between time varying mesh stiffness and clearance non-linearities in a geared system. J Sound Vib 1991; 146(1): 135-156.

19. Kahraman A. Effect of axial vibrations on the dynamics of a helical gear pair. J Sound Vib 1993; 115(1): 33-39.

20. Benton M and Seireg A. Factors influencing instability and resonance in geared systems. J Mech Des 1981; 103(2): 372-378.

21. Benton $M$ and Seireg A. Simulation of resonances and instability conditions in pinion-geared systems. J Sound Vib 1978; 100(1): 26-32.

22. Blankenship GW and Singh R. A new gear mesh interface dynamics model to predict multi-dimensional force coupling and excitation. Mech Mach Theory 1995; 30(1): 43-57.

23. Blankenship GW and Singh R. Dynamic force transmissibility in helical gear pairs. Mech. Mach. Theory 1995; 30(3): 323-339.

24. Gu X, Velex P. On the dynamic simulation of eccentricity errors in planetary gears. Mech. Mach. Theory 2013; 61: 210-229.

25. Velex P, Sainaot P. An analytical study of tooth fraction excitations in errorless spur and helical gears. Mech. Mach. Theory 2002; 37(7): 641-658.

26. Brethee KF, Zhen D, Gu FS, et al. Helical gear wear monitoring: Modelling and experimental validation. Mech. Mach. Theory 2017; 117: 210-229.

27. Park D, Kahraman A. A surface wear model for hypoid gear pairs. Wear 2009; 267 (9-10): $1595-1604$

28. Bahk CJ, Parker RG. Analytical investigation of tooth profile modification effects on planetary gear dynamics. Mech. Mach. Theory 2013; 70: 298-319.

29. Xun C, Long XH, Hua HX. Effects of random tooth profile errors on the dynamic behaviors of planetary gears. J Sound Vib 2018; 415: 91-110.

30. C. Li, S. Zhou, J. Liu, B. Wen. Coupled lateral-torsional-axial vibrations of a helical gear-rotor-bearing system, Acta Mech Sin 2014; 30: 746-761.

31. Zhang YM,Wang Q and Ma J, et al. Dynamic analysis of three-dimensional helical geared rotor system with geometric eccentricity, J. Mech. Scie. Technol, 2013;27: 3231-3242.

32. Yu WN, Mechefske CK, and Timusk M. The dynamic coupling behaviour of a cylindrical geared rotor system subjected to gear eccentricities. Mech. Mach. Theory, 2017; 107: 105-122.

33. Xiang, L. and N. Gao. Coupled torsion-bending dynamic analysis of gear-rotor-bearing system with eccentricity fluctuation. Applied Mathematical Modelling, 2017; $50: 569-584$.

34. Yao Y, Zhang H, Li YM, et al. The dynamic study of locomotives under saturated adhesion. Veh Syst Dyn 2011; 49: 1321-1338.

35. Huang GH, Zhou N and Zhang WH. Effect of internal dynamic excitation of the traction system on the dynamic behavior of a high-speed train. Proc IMechE, Part F: J Rail and Rapid Transit 2016; 230: 1899-1907.

36. Chen ZG, Zhai W and Wang K. A locomotive-track coupled vertical dynamics model with gear transmissions. Veh Syst Dyn 2017; 55: 244-267.

37. Chen ZG, Zhai WM and Wang KY. Locomotive dynamic performance under traction/braking conditions considering effect of gear transmissions. Veh Syst Dyn, 2018; 56(7): 1097-1117.

38. Wang ZW, Zhang WH, Yin ZH, et al. Effect of vehicle vibration environment of high speed train on dynamic performance of axle box bearing. Veh Syst Dyn 2019; 57(4): 543-563.

39. Wang ZW, Mei GM, Xiong Q, et al. Motor car-track spatial coupled dynamics model of a high-speed train with traction transmission systems. Mech Mach Theory 2019, 137: 386-403.

40 Wang ZW, Song Y, Yin ZH, et al. Random response analysis of axle-box bearing of a high-speed train excited by crosswinds and track irregularities[J]. IEEE Transactions on Vehicular Technology, 2019, DOI: 10.1109/TVT.2019.2943376.

41 Li RF and Wang JJ, Gear transmission system dynamics, Since Press, Beijing, China (1997).

42. Timoshenko, S. Vibration Problems in Engineering, 4th edn. Wiley, USA (1974).

43. Liang, L., Xiao, X.B., Xiong, J.Y., Zhou, L., Wen, Z.F., Jin, X.S.: A 3D model for coupling dynamics analysis of high-speed train/track system. J. Zhejiang Univ. Sci. A, Appl. Phys. Eng. 15(12), 964-983 (2014)

44. Chen G, Zhai WM. A new wheel/rail spatially dynamic coupling model and its verification, Veh Syst Dyn. 2004;41(4):301-322. 
45. Shen ZY, Hedrick JK, Elkins JA. A comparison of alternative creep force models for rail vehicledynamic analysis. Veh Syst Dyn 1983;12(1-3):79-83.

46. Kalker JJ. Three-dimensional elastic bodies in rolling contact. Vol. 2. Dordrecht: Springer Science \& Business Media; 1990.

47. Han J, Zhong S, Xiao X, et al. High-speed wheel/rail contact determining method with rotating flexible wheelset and validation under wheel polygon excitation[J]. Vehicle System Dynamics, 2018, 56(8): 1233-1249. 